\title{
Topical Analysis of Nuclear Experts' Perceptions of Publics, Nuclear Energy, and Sustainable Futures
}

\author{
Hannah K. Patenaude ${ }^{1,2,3 *}$ and Emma Frances Bloomfield ${ }^{2,3}$ \\ ${ }^{1}$ Department of Chemistry and Biochemistry, University of Nevada, Las Vegas, Las Vegas, NV, United States, ${ }^{2}$ Department \\ of Communication Studies, University of Nevada, Las Vegas, Las Vegas, NV, United States, ${ }^{3}$ Public Communication Initiative, \\ Las Vegas, NV, United States
}

OPEN ACCESS

Edited by:

Brianne Suldovsky,

Portland State University,

United States

Reviewed by:

Danielle Endres,

The University of Utah, United States

Julie Schweitzer,

Oklahoma State University,

United States

${ }^{*}$ Correspondence:

Hannah K. Patenaude patenh1@unlv.nevada.edu

Specialty section:

This article was submitted to Science and Environmental Communication,

a section of the journal Frontiers in Communication

Received: 21 August 2021 Accepted: 20 January 2022 Published: 11 February 2022

Citation: Patenaude HK and Bloomfield EF (2022) Topical Analysis of Nuclear Experts' Perceptions of Publics,

Nuclear Energy, and Sustainable Futures. Front. Commun. 7:762101. doi: 10.3389/fcomm.2022.762101
Nuclear energy experts consider commercial power from fission to be a strong contender to help mitigate the increasing effects of climate change, in part due to its low-to-no carbon emissions. Nevertheless, nuclear energy's history, including meltdowns such as Three Mile Island, Chernobyl, and Fukushima, and dumping in sacred Indigenous land such as Yucca Mountain, raises important concerns in public deliberation over nuclear power. These communicative dynamics are crucial to study because they inform larger conversations in communication scholarship about the role of experts in scientific controversies and the complicated nature of public trust in and engagement with science. Thus, this study explores the perspectives of experts and how they make sense of their own communicative practices through a topical analysis of semi-structured interviews with 12 nuclear scientists and engineers in the United States and Canada. Our analysis revealed four major topoi: (1) risk and safety, (2) government and policy, and (3) public education and engagement, and (4) cost, along which nuclear experts make sense of science-public boundaries and their role as scientists and scientist citizens. This paper extends our understanding and how scientists view themselves as communicative actors and the barriers and opportunities for how we can foster productive technical-public relationships around climate change solutions.

Keywords: energy rhetoric, nuclear energy, topoi, scientist citizens, climate change, monologue, dialogue

\section{INTRODUCTION}

In our current age of environmental crises, there is a pressing need to foster relationships between technical and public actors to together establish sustainable futures. One area of scientific study aimed at exploring viable alternatives to fossil fuels is nuclear energy, which harnesses the unparalleled release of energy from splitting atoms. Trust in nuclear scientists and purveyors of nuclear power directly affects public opinion on subsequent acceptance of nuclear energy (Ho et al., 2019), making them key figures in nuclear energy deliberation. Nuclear energy, much like the larger, "wicked," interdisciplinary problem of climate change (Cagle and Tillery, 2015), is made up of seemingly disconnected "institutions, practices, and a dense network of representations and meanings" (Kinsella, 2005, p. 49). Wading into these complicated arenas is often not a priority for scientists, who may not have access to communication training or the incentives to seek out those resources. Consequently, science communicators often "speak of [science] more elegantly than the very scientists themselves" (Fahnestock, 1986, p. 331), leading to divides between scientists and the public not unlike the scientific controversies of climate change and the COVID-19 pandemic. 
Scientists may be wary of public engagement because they do not want to be viewed negatively by other scientists or face harassment and backlash from the public (Waldman and Heikkinen, 2018). Some scientists fear the "Sagan effect," named after astrophysicist and Cosmos host Carl Sagan, which correlates an expert's amount of public interaction and media attention with less professional competence (Ecklund et al., 2012). Additionally, scientists may be penalized by both technical and public actors for seeming to cross the acceptable boundaries of science into politics (Walsh, 2010; Latour, 2014). Fortunately, research by Kotcher et al. (2017) suggests that some of these fears may be exaggerated, as their study found that scientists' credibility and trust in science was largely unaffected by public advocacy statements.

The study's one exception to this trend was the scientist who advocated for building more nuclear power plants (Kotcher et al., 2017). This scientist's perceived credibility did suffer when making advocacy statements, thereby demonstrating the fraught nature of public communication around nuclear energy and the various risks scientists take when engaging with public audiences on the topic (Kotcher et al., 2017). These perceived and potential risks of technical-public interactions dampen interest in public science communication and consequently hamper the most "promising candidates for bridging technical and public knowledge," scientists themselves (Pietrucci and Ceccarelli, 2019, p. 101). Pietrucci and Ceccarelli (2019) argue that scientists are the best bridges between the technical and public spheres because "they dwell in both" (p. 101). But, if technical experts, such as nuclear scientists, are fearful of such interactions, we may be "left with a dangerous gap between science and the public that can have disastrous results" (Pietrucci and Ceccarelli, 2019, p. 98).

These breakdowns between technical and public actors in our current moment could lead to inaction on environmental and health crises such as climate change and the COVID19 pandemic, resulting in the loss of life, disproportionately across vulnerable and marginalized communities, and a failure to protect future generations and the planet (e.g., Sowards, 2012; Holifield et al., 2017; Reverby, 2021). Technical-public communication is thus integral to intervening in our various crises, especially environmental ones, because they center discussions of science, trust, expertise, and collaboration. Within the larger conversation about environmental crises, we focus on nuclear energy as a ripe arena for assessing public-technical dynamics and how scientists are making sense of their dual roles as scientists and science communicators. Simply put, nuclear scientists not valuing technical-public interactions can create barriers to conversation and collaboration that shut concerned publics out of energy deliberation.

For example, technical-public collaborations on nuclear energy might help overcome barriers to public participation, create regulations around nuclear waste, and leverage the potential benefits of nuclear energy while reducing its negative impacts. For example, research shows that nuclear energy could help combat the effects of climate change (Besley and Oh, 2013; Serp et al., 2017; Prăvălie and Bandoc, 2018), provide certain health and medical benefits (Kharecha and Hansen, 2013; Hacker et al., 2015), and contribute to global biodiversity conservation (Brook and Bradshaw, 2014). There are considerable drawbacks and concerns about nuclear energy, however, that necessitate public involvement and the incorporation of local, community needs with science. Evaluating the benefits and harms of nuclear energy with the expertise and experiences of both scientists and publics becomes more urgent as time passes and the consequences of the climate crisis loom ever larger.

This study thus joins a growing interdisciplinary interest in nuclear energy and nuclear experts. Many scholars who analyze nuclear rhetoric do so by highlighting public voices such as competing industries, anti-nuclear organizations, political groups, activists, and affected populations (e.g., Stoffle and Evans, 1988; Lynch, 2012; Goodin, 2013; Hynes, 2013; Thakur, 2013; Zhu et al., 2016). In their editorial introduction to a special issue of Environmental Communication, Ho and Kristiansen (2019) note that most studies of nuclear energy focus on media coverage of accidents and public opinion. Pointing to noticeable gaps in the literature, they call for more studies of nuclear energy that attend to long-term messaging, international comparative studies, and digital media's role in nuclear communication (Ho and Kristiansen, 2019). Missing from this list, but we feel necessary to add, is technical nuclear rhetoric, or discourse from within the technical sphere of nuclear energy.

Technical rhetoric in the nuclear energy industry has been a marginal area of study in communication, with notable exceptions (e.g., Kinsella, 1996, 1999; Endres et al., 2016; Summers et al., 2019). These studies have primarily been guided by ethnographic methods, making our methodology of interviews an opportunity to expand our understanding of how nuclear experts make sense of technical-public relationships and their careers in their own words. Scholars in other disciplines, such as sociology and policy studies, have begun engaging in such work (e.g., Shim et al., 2015; Harris et al., 2018; Saraç-Lesavre and Laurent, 2019; Schweitzer and Mix, 2021a,b). Schweitzer and Mix (2021a,b), for example, interviewed nuclear experts, advocates, and opponents in France, a country more familiar with nuclear power.

As a preliminary look into how nuclear scientists and engineers conceptualize public-technical interactions, this study performed a topical analysis of the personal perspectives of a small group of nuclear experts. In 2018, we performed semistructured interviews with 12 nuclear scientists and engineers recruited via snowball sampling based on interest, availability, and expertise. All experts have obtained graduate degrees within a range of specific nuclear disciplines and with varying lengths of time participating in the nuclear industry (see Table 1). Questions (see Appendix) addressed the state of nuclear energy communication in North America. Interviews were conducted until saturation was reached regarding repeated themes and patterns. While this particular pool of individuals does not represent the views of all nuclear specialists, our topical analysis of these interviews reveals important areas for understanding the technical community's perspective on nuclear energy and public-technical interactions.

Topical analysis, which focuses on the appearance of topoi, or commonplace topics, reveals patterns and lines of argument. Topical analyses have previously been used to explore 
TABLE 1 | Interviewee details.

\begin{tabular}{lll}
\hline Interviewee & Job description & Starting decade in the nuclear industry \\
\hline 1 & Radiochemist & $2010 \mathrm{~s}$ \\
2 & Nuclear physicist & $2000 \mathrm{~s}$ \\
3 & Radiochemist & $1990 \mathrm{~s}$ \\
4 & Nuclear engineer & $1990 \mathrm{~s}$ \\
5 & Nuclear physicist & $1990 \mathrm{~s}$ \\
6 & Nuclear engineer & $1970 \mathrm{~s}$ \\
7 & Nuclear engineer & $2010 \mathrm{~s}$ \\
8 & Nuclear engineer & $2000 \mathrm{~s}$ \\
9 & Nuclear engineer & $2000 \mathrm{~s}$ \\
10 & Nuclear physicist & $1980 \mathrm{~s}$ \\
11 & Nuclear engineer & $1960 \mathrm{~s}$ \\
12 & Nuclear engineer & $2010 \mathrm{~s}$ \\
\hline
\end{tabular}

environmental rhetoric in digital spaces and interviews (e.g., Ross, 2017; Cagle and Tillery, 2018; Tillery, 2018; Bloomfield and Tillery, 2019). Ross (2017) argued that topoi "appear operational as both generic, inventional topics and contextsensitive, argumentative heuristics" (p. 94). For example, nuclear scientists using terms such as "risk" may simultaneously be addressing broad categories of risk management, inherent risks in science, and specific risks from nuclear practices and accidents. Topoi can play an essential role in the process of "invention," through which ideas for argumentation, communication, and shared ground for collaboration emerge (Cagle and Tillery, 2018, p. 136).

In what follows, we offer a brief timeline of important moments in nuclear energy's history. Then, we describe the literature on public-technical relationships, the "scientist citizen," and dialogue that guides our analysis. Then, we interpret the interview data across four topoi that emerged during the interviews: (1) risk and safety, (2) government and policy, (3) public education and engagement, and (4) cost. We argue that these topoi manifested as inventional resources through which nuclear experts made sense both of their own roles as nuclear experts and of technical-public relationships. Together, these topoi provide insight into the rhetorical dynamics of nuclear energy from a technical perspective, albeit one that was variable and non-monolithic. We largely found that experts deploy features of both monologue and dialogue, which points toward barriers to technical-public engagement on nuclear but also potential opportunities. We conclude by considering future directions for research into nuclear energy communication and how these topoi might also constrain and inform other scientific topics.

\section{IMPORTANT MOMENTS IN NUCLEAR ENERGY'S HISTORY}

Controversies are rarely wholly novel; instead, they are reemergences of "well-known paths of argument" that may become "dormant" but then "reappear" later (Goodnight, 2005, p.
27). In thinking of contemporary controversies over nuclear energy, it is useful to contextualize issues of "approach and avoidance, fear and hope, [and] risk and security" that have threaded through nuclear energy's history and informed our current moment (Goodnight, 2005, p. 26). In particular, nuclear energy's history tells a story of political and military priorities outranking public, local, and Indigenous concerns, in addition to long-standing issues with safety and risk management that help explain historical and contemporary skepticism toward nuclear energy.

A history of nuclear energy arguably starts with the discovery of uranium and radium in 1896 and 1902, respectively. The early twentieth century saw an explosion of interest in groundbreaking scientific discoveries using these materials, until it was discovered that they were highly toxic (Santos, 2021). In 1934, Irène Joliot-Curie and her husband Frédéric discovered artificial radioactivity, the fundamental science behind nuclear weapons. By the early 1940s, construction had started on the three primary locations for the development and construction of nuclear weapons: Los Alamos, New Mexico; Richland, Washington; and Oak Ridge, Tennessee (National Atomic Testing Museum, 2021).

These construction projects displaced Native Americans who had occupied the land for thousands of years. Many Native Americans continued to return to their sacred religious and cultural lands until the U.S. government installed physical barriers and armed security (National Atomic Testing Museum, 2021). A specific controversy over nuclear waste storage erupted when the Yucca Mountain Nuclear Waste Repository was established by the Nuclear Waste Policy Act of 1987 to serve as a disposal site for used fuel and other high-level radioactive wastes. In response, the Western Shoshone National Council issued land permits to anti-nuclear protestors at the Nevada Test Site and filed a federal lawsuit citing the 1893 Treaty of Ruby Valley that showed the land was never given to the US (Klenke, 2020). Although storing nuclear waste at Yucca Mountain is now "effectively off the table" (Klenke, 2020), the battle has been hard fought and illustrates the tensions between nuclear energy and Indigenous populations, lands, and sovereignty (Endres, 2009b).

In addition to displacing Native Americans and damaging Indigenous lands, nuclear energy was also used as a weapon of war. The first-ever nuclear weapon was detonated on July 7 , 1945, and shortly thereafter, the Little Boy (August 6) and the Fat Man (August 9) were dropped on Hiroshima and Nagasaki, Japan, respectively, resulting in the country's surrender in World War II on August 14. The total number of casualties, injuries, and affected lives is not exactly known but is estimated to have taken the lives of upwards of hundreds of thousands of people (Tomonaga, 2019).

In 1953, then-President Eisenhower introduced the "Atoms for Peace" campaign aimed at quelling concerns about nuclear energy and committing the US to "peaceful" uses of the material, while the US and the Soviet Union increased their control and infrastructure of nuclear warheads (Kinsella et al., 2015). In 1954, Eisenhower signed the Atomic Energy Act that supported the development of atomic energy for peacetime 
uses, specifically the future of commercial nuclear power. The simultaneous development of wartime and peacetime uses of nuclear energy sent conflicting messages about its safety and functions.

Further complicating public support of nuclear energy was a history of accidents at nuclear power plants. One of the first accidents happened in 1950 when the Chalk River research reactor was mishandled, resulting in a meltdown and release of radioactive material into the environment (Lewis, 1953). In 1979, Allen et al. vs. the United States of America was filed by residents downwind from the Nevada Test Site, many of whom had developed cancers due to their proximity to the nuclear tests (National Atomic Testing Museum, 2021). 1979 was also the year that the Three Mile Island plant suffered a meltdown and channels for emergency communication failed, causing public trust in nuclear to be irreparably damaged (Farrell and Goodnight, 1981; Endres et al., 2016). One of the most famous nuclear meltdowns, the Chernobyl disaster, occurred in 1986 as a result of human error both in the operation and management of nuclear technology in the Soviet Union (Rich, 1986). Throughout the 1980s, the Cold War was at the front of everyone's minds (Gusterson, 1996), especially those running in the international nuclear arms race. These circumstances only strengthened the association of nuclear technology and nuclear professionals with militarization, weapons, and secrecy (Kinsella et al., 2015). In 2011, an earthquake resulting in a tsunami caused a meltdown in the Fukushima Daiichi nuclear power plant. Although the meltdown event did not result in any immediate deaths, the communication regarding the accident was contaminated (Kinsella, 2012; Endres et al., 2016), and public trust deteriorated with the reactor core (Kim et al., 2013; Tateno and Yokoyama, 2013; Besley and Oh, 2014; Endres et al., 2016).

The history of nuclear technology is riddled with controversies, corruption, lawsuits, and violated treaties, providing important context to public skepticism of nuclear power and the dynamics that influence potential public-technical collaboration on these topics. In order to build trust with a skeptical public and prevent further atrocities from occurring, it is imperative that the flow of information between the technical and public spheres include not only information from the technical to the public, but also participation and feedback from the public to the technical. Themes of colonialism, eminent domain, and Indigenous displacement are far too common and mostly unresolved as the industry moves forward without addressing past atrocities. If these rhetorical blockades can be broken down, there may be hope for technical-public collaboration on nuclear energy's future that involves the public as a key stakeholder and engages nuclear experts in the moral, reciprocal features of being bridges between technical and public arenas.

\section{MONOLOGUE AND DIALOGUE IN INTERVIEWS WITH NUCLEAR EXPERTS}

Following Bloomfield and Tillery's (2019) methodology, we first identified "recurring themes" in the interviewee responses and organized those under commonality and shared meaning (p. 25). Then, we analyzed those themes for constructions of publictechnical relationships and their personal role as scientists. These interpretations are informed by scholarship on scientist citizens (Pietrucci and Ceccarelli, 2019), dialogue (Johannesen, 1974; Bloomfield, 2019a), and science-politics boundaries (e.g., Walsh, 2010; Latour, 2014) to examine how scientists make sense of their communicative practices. Within each topos, we first analyze evidence that experts engage a monologue and reinforce sciencepublic boundaries. Then, we discuss evidence that the experts engage a scientist citizen identity and a dialogue approach to science-public boundaries.

"Scientist citizen" is a term that emphasizes the dual identity of scientists as simultaneous public and technical actors. Emphasizing this dual identity, Pietrucci and Ceccarelli (2019) argue that scientists have a "special responsibility" to engage in public-facing work rooted "in moral values (arête), goodwill (eunoia), and practical judgment (phronesis)” (pp. $101,98)$. In other words, scientists' credibility is a matter not only of scientific expertise but also of their public evocation of morality, benevolence, and thoughtful action. In a different article, Ceccarelli (2020) elaborated that a scientist citizen's arête involves a commitment "to the virtue of honesty" and phronesis involves a sense of prudence and timing specific to particular contexts and situations (p. 242). Eunoia is often directly translated as "goodwill," but also means "approval, sympathy, and readiness to help" (de Romilly, 1958 , p. 92). We thus locate qualities of honesty, virtue, prudence, readiness to help, and sympathy as characteristics of scientist citizens, which can foster opportunities for publictechnical engagement.

By traversing the spheres, the scientist citizen persona calls into question what is traditionally viewed as appropriate scientific actions. Walsh (2010) calls this divide the "is/ought boundary," which denotes how scientists should normatively operate in the realm of knowledge, states of existence, and fact-gathering (i.e., "what is the severity and urgency of climate change?"), while political actors operate in the realm of action, policy, and deliberation (i.e., "what ought we to do about it?"). Latour (2014) framed this divide as "science-vs.-politics" (p. 147). Notions that science should only be concerned with communicating facts distinguishes technical and public stakeholders as having or not having knowledge, respectively, as opposed to respecting varying expertise and backgrounds as differently valuable (Endres, 2009a).

Focusing on a lack of knowledge evokes the information deficit model (IDM), which argues that filling a knowledge gap will increase public agreement with the topic at hand (Gross, 1994). Ultimately, studies have provided evidence that the IDM is an oversimplified model and that differences in knowledge are not solely responsible for lack of agreement between technical and public actors (Marteau et al., 2002; Bloomfield et al., 2020). Additionally, some studies argue that providing information that focuses on information gaps can create backfire effects, lead audiences to feel the information is personally irrelevant to them, and make conversations more difficult (Hart and Nisbet, 2012; Fernández, 2016; McFadden, 2016). 
Based on the terminology of Johannesen (1974), we describe discourse that embraces the scientist citizen role, focuses on bridging science-public divides, and sees public audiences as equals as engaging in "dialogue." Alternatively, we describe discourse that focuses on information deficits, concretizes science-public divides, and views public audiences as inferior to scientists as engaging in "monologue." These two overarching terms organize our topical analysis to show how varied nuclear experts' attitudes are toward technical-public interactions and how monologue can stifle productive engagement and reify boundaries between scientists and the public. We now turn to our interviews with nuclear experts and show how attitudes of monologue and dialogue emerged across three of the topoi, risk and safety, government and policy, and public education and engagement, with the fourth topos, cost, dominated by monologue.

\section{Risk and Safety}

Risk and safety, collectively, was the most prominent topos expressed by nuclear experts, indicating a recognition of public concern over the risks of nuclear energy and radioactivity. It is often assumed that scientists and engineers perceive risk differently, guided by numbers, data, and statistics (quantitative risk), which is distinct from publics who largely conceptualize risk on a more personal and community level (qualitative risk). Consequently, it may be challenging for scientists and engineers to translate risks accurately due to the incompatibility of interests and frameworks from which experts and the public operate.

\section{Monologue}

Monologue in the risk and safety topos primarily appeared in devaluing the public's fears over nuclear risks and thereby treating public audiences as inferior conversation partners. For example, participant 1 noted, "people are afraid because they do not understand; people who understand embrace it." While this may be true for select instances in this expert's experiences, it is important to note that these perceptions overemphasize knowledge as influencing acceptance of science (e.g., McFadden, 2016). Furthermore, this comment views nuclear fears as primarily coming from ignorance, undercutting the knowledge and rationality of those concerned about nuclear risks. A majority (eight) of the experts interviewed said that events like major nuclear accidents have significantly inflated the public's fear of radiation, inherently increasing public perceptions of the risk associated with nuclear power plants.

Statements from interviewees indicated that most felt the public's fears were not reasonable, thus downplaying the rationality of the public. Discussions of nuclear fears as irrational is called "radiophobia," which is a strategy to de-prioritize public concerns over nuclear energy used after the Chernobyl disaster (Novikau, 2017). Some of these comments indicate that interviewees believe that public fears can be blamed mostly on their own misunderstandings, instead of recognizing how the industry has helped to manifest those perceptions.

Many interviewed experts (nine) believe that nuclear energy is safer than most people think, which prevents agreement with technical experts. For example, participant 3 explained that as the "current [domestic] fleet of reactors is aging, [...] people are trying different reactor designs" that enhance safety, security, and efficiency. Participant 3 refers to new reactors being built with increased safety measures since the most recent accident at Fukushima Daiichi. Participant 7 thinks that nuclear "has the most strict regulatory requirements" compared to other energy options and that these advantages "should be communicated better" to ease public worries about safety and relative risks. In emphasizing communication simply as knowledge-transfer, these participants deploy a monologue and see public audiences at a knowledge deficit that increased communication can correct. It is important to note that a blanket call for communication is not in and of itself dialogue; dialogue is a specific type of communication that values everyone's perspectives. These comments, therefore, are more closely akin to a monologue that assumes people will eventually agree with the "right" perspective, the nuclear industry's perspective, with more information and dismisses disagreement with experts as ignorance of the topic.

Despite a focus on risk related to nuclear accidents, few interviewees addressed risks associated with storing nuclear waste. This is a notable absence because waste is a prominent topic, as previously mentioned, for Indigenous communities and marginalized populations. These responses suggest that this is not an issue at the forefront of experts' considerations of nuclear risk, thereby further marginalizing local populations that are dismissed by attitudes of nuclear colonialism in the US (Endres, 2012, p. 329).

\section{Dialogue}

The risk and safety topos also contained evidence of dialogue. In consideration of how risk affects everyone, participant 8 said that nuclear experts must have "respect for society, safety, and [society's] wishes for the types of risks they want to take." Deploying a sense of respect and goodwill (eunoia) toward the public, participant 8 centers the public's perception of risk and safety. Despite previously evoking a monologue perspective, participant 7 also recognized the unfortunate tendency for experts to ignore the public. Participant 7 noted, "people [in the nuclear industry] do not really have empathy for the public and dismiss them as uneducated" when attempting to address people's concerns about the risks and safety related to nuclear power. Participant 7 believes that instead of dismissing these concerns, they should be engaged with empathy, also demonstrating eunoia toward public audiences.

Many interviewees recognized various sources of fear as legitimate ones: infamous accidents, extensive atomic testing above and below sea level, and government mishandling of nuclear materials and projects around the world. Participant 6 recalls that "after Three Mile Island, the type of research we pursued changed" to prioritize the safety features that prevent such an event from happening again in the future. Instead of dismissing the public's fears, participant 6 engages in phronesis, or practical judgment on the proper direction of nuclear research based on evolving public concerns around risks.

Over half of the experts interviewed explicitly mentioned that no form of nuclear power is free of risk, thereby acknowledging that public fears are, at least in part, reasonable. These beliefs 
are similar to those recorded by Schweitzer and Mix (2021b) in France, who found nuclear experts believed that "there is no such thing as zero risk' when talking about nuclear safety" (p. 9). In the words of participant 10, nuclear energy "should be a part of any energy solution," but "we should all be making rational decisions with the sum of all risks." This statement blends phronesis and eunoia in valuing public concerns and making decisions while considering various perspectives. While it is unclear whether nuclear waste and marginalized communities are included in this calculation, the general sentiment indicates that rational decisions should engage various forms of risks instead of dismissing them as unreasonable. Some interviewees perceive safety as a priority for the industry more than ever before, but as an area that can always use more attention.

Three of the interviewees shared personal experiences when talking about the risk associated with nuclear power. After Fukushima, participant 7 worked with communication experts in an "eye-opening experience" where they collaboratively gathered members of the public to talk about the state of the environment after the accident. This experience showed participant 7 firsthand the importance of framing risk to help ease concerns. Participant 7 recognized the different ways that publics might response to risk and said, "instead of saying 3\% [of an area] is contaminated, say $97 \%$ is not contaminated" to emphasize where they do have control over contamination, rather than where they do not. This process is done with the hopes of engaging what will be the most effective communication with an audience that is likely under high stress and concerned for their own wellbeing. Recognizing these communicative differences frames participant 7 as aware of their role as communicators and the dynamics of communicating risk.

Participant 12 demonstrated an understanding of audience adaptation and the power of metaphor to communicate nuclear risks. In talking about nuclear energy as a tool that can be used to combat climate change, participant 12 noted, you "could chop down a tree with a pocket knife, but you'd probably like to use a saw." Of course, the risk of being hurt by a saw is much higher than that of a pocket knife, but both tools, each with their relative risks, can be used carefully and thoughtfully to get the job done. For participant 12, nuclear energy is a saw that is a better fit to cut down carbon emissions than other energy sources. This comment demonstrates attention to how to communicate energy choices to public audiences and also recognizes the inherent risks of nuclear energy and their hopes it can be a tool used for climate mitigation. Participant 2 expressed a similar hope that nuclear power may be adapted to meet the "needs [of] energy and environmental concern $[s]$ " by making it safer.

Participant 11 also used a metaphor to compare added regulations for nuclear to vehicles: "if you have a parking brake and a foot brake on your car, do we need to add three more braking systems? No, but technically it would be safer." This participant used this metaphor to illustrate how additional regulations may lead to perceptions of safety but may instead be redundant and unnecessary, but in a way that does not necessarily "dumb down" the technical concept, but rather places it within a frame of reference likely familiar to public audiences. These interviewees are, in part, recognizing their roles as citizen scientists (Pietrucci and Ceccarelli, 2019) by considering audience adaptation and embracing a role as bridge-builders that communicate technical information to public audiences about risk and safety.

Although nuclear communication has proven to be a risky activity, participants were hopeful that the next generation of nuclear experts would improve public-technical relationships. In particular, participant 7 hopes that the nuclear community will learn more about the "environmental impacts of nuclear" technology when making risk assessments, and feels that as a materials and environmental scientist, "nuclear engineers do not [yet] understand the impacts" fully. Participant 8 thinks there will be "a lot of opportunity for independence [of] thought and creativity which hopefully does not come with repeating mistakes from the past," including downplaying risks. They continued by noting that there is a "lot of opportunity to change the culture of the nuclear industry" to be more open, honest, and transparent (arête and eunoia).

Participant 5 echoed concerns that nuclear communication has been fraught with issues of transparency and accuracy, noting that past statements from the industry framed nuclear reactors as "fool-proof." Drawing a connection to the Titanic being "unsinkable," participant 5 noted that "determining how to limit liability does not go well with "fool-proof" reactors." In other words, previous assertions of universal safety have been proven wrong, which reasonably inspires suspicion of contemporary claims of nuclear's safety. Instead of reiterating false claims of reactors being "fool-proof," participant 5 offers that nuclear communication should focus on translating the nuances that prevent nuclear energy from being labeled honestly as either "safe" or "unsafe." By advocating for truth, accuracy, and transparency, they echoed the scientist citizen's moral virtues (arête).

Six additional interviewees agreed with participant 5 that it is not public fears that have been the main problem for nuclear, but rather how nuclear relative risks and safety have been communicated. These comments shift blame from the publics' understanding of risk to the nuclear industry's lack of open, clear communication about them. By addressing known areas of uncertainty with compassion and the public's best interest in mind, these nuclear experts expressed an interest in building trust between the public and technical spheres.

\section{Government and Policy}

Another topos expressed by interviewees is the industry's dependence on government regulation and policy. The monologue and dialogue components of government and policy emerged in how experts made sense of the priorities of policy makers and legislators in relation to nuclear energy. As a result, monologue and dialogue reflect experts' reification or challenging of the science-vs.-politics divide.

\section{Monologue}

While cost emerged as a separate topos, issues of funding were also tied to experts' relationship with the government. Interviewee 3 explained that their "life is based on getting funding from mostly the government." Seven experts agreed, 
stating that their primary interaction with politics and policy is through aligning their proposals and interests with the political party in power. As one participant noted, there have been instances where Congress decreased "funding to certain projects where people have lost [working] relationships because of new sanctions regarding foreign relationships" (participant 1), only strengthening the expert's perception of a science-policy divide. These shifts in political administrations have marked effects on the ability of nuclear experts to do research and maintain valuable collaborations around the world. When these relationships and projects get disrupted, the government can be viewed as an enemy to science and to progress.

The interviewees unanimously lamented that the US has yet to provide a clear, consistent energy policy. Participant 10 stated that "we have no national energy policy," just a "mish-mosh of politics, greed, and dissociated energy costs." Participants generally described nuclear power as having to operate within a complex, politically charged sector of society that can be influenced by political power and greed. Evoking an inferior view of publics, participant 2 thinks that "there is not enough information for the public to have an opinion" either way on nuclear energy, which means political leaders find it hard to represent the public's priorities. This is not a concern to participant 2, however, as long as "those making decisions know how it works," thereby tacitly encouraging a dismissal of public concerns by politicians. Instead of making practical decisions with publics in mind, participant 2 rejects phronesis in favor of interfacing with political elite devoid of public participation. This interviewee thought that politicians were not necessarily fully rational actors either, noting that the "problem comes when we do not make decisions based on science and facts" and, alternatively, make decisions based on partisan goals. Noting that governments have been corrupted by both money and political loyalties (Cloud, 2020), participants separate themselves as above these concerns and see science as wholly rational when compared to politics, thereby deepening science-politics divides.

\section{Dialogue}

Although many interviewees had less than positive perceptions of government and politics, some interviewees embraced politics and saw it as integral to their career. For example, participant 5 describes their job as "correcting government officials in different countries who have made wrong statements" about nuclear power. Although "correcting" certainly implies a monologue approach to politicians and publics as inferior to scientists, the focus on engagement with politicians also reflects the arête of a scientist citizen. Pietrucci and Ceccarelli (2019) argued that when scientists fail to correct public officials, they wrongfully abdicate their responsibility to the truth and to the wellbeing of society. Through this perspective, participant 5 can be seen as evoking a scientist citizen identity where scientists view themselves as responsible for the accurate communication of their science and for intervening in public misconceptions.

Noting how "politics affect everything," participant 11 communicated how important it is for elected representatives to follow the views of their constituents and, therefore, how important communication of nuclear energy science is to both public audiences and policymakers. Without including the public, legislation becomes hierarchical and exclusive, resulting in the perpetuation of skepticism and fear. A few (three) of the interviewees explicitly mentioned that the public has limited trust in both the government and nuclear industry leaders, making them allies in the work to be more transparent and trustworthy (arête). Thus, participants argued that the nuclear industry and nuclear experts must work collaboratively with politicians. Instead of emphasizing a divide between politics and science, these interviewees embraced the linkages between them as integral to productive and ethical energy decision-making (phronesis). Unlike the topos of risk and safety, the topos of government and policy was dominated more by monologue than dialogue, but there were undercurrents of collaboration, phronesis, and arête.

\section{Public Education and Engagement}

Engaging and educating the public is another topos that emerged in interviewees' responses. As discussed in the risk and safety topos, discussions of knowledge can easily slide into a monologue framework, but discussions of engagement are more promising for dialogue. Under this topos, a monologue perspective often accompanied assumptions of ignorance, willful or otherwise, while a dialogue perspective accompanied empathy and attempts to incorporate public participation directly into the science. From both perspectives, the ultimate goals of public education and engagement center around doing what the interviewees believe is in the best interest of the public.

\section{Monologue}

Responses that evoked a monologue perspective echoed feelings of public ignorance and expressed what experts felt was undeserved scorn for their careers. Similarly, one nuclear expert in France claimed that lies that are "internalized by the public opinion ensure that almost everybody is extremely ignorant regarding the real situation of this industry" (Schweitzer and Mix, 2021b, p. 10). The lack of accurate information and the spread of what they refer to as lies makes them reticent to engage with the public about their careers, as expressed by participant 3 in our study who has felt people "look at [them] in a weird way for wearing a pro-nuclear shirt." Other participants reported that their early predecessors in the industry were often quick to shut down conversations that questioned the abilities of nuclear power when discussing nuclear with public audiences. Participant 10, for example, said they "do not bring up what [they] do at dinner parties," assuming they would be met with mixed and potentially even combative responses. Exhibiting what could be called radiophobia-phobia, this participant feared that they would be perceived as dismissive or elitist due to the actions of other nuclear experts, and therefore withdrew from engaging publicly with their careers. Participant 10 further characterized their reluctance to discuss their career in nuclear. They noted, that, in general, "scientists are well-trusted, but when it comes to nuclear there's mistrust." 
Existing mistrust and also the perception of that mistrust can encourage nuclear experts to separate their careers from their public interactions, thereby contributing to further mistrust and secrecy. Instead of fostering a scientist citizen identity who builds bridges to the public, fears around public engagement can construct a science-citizen Rawlsian curtain that cleaves each identity from the other. The mistrust of nuclear energy and the subsequent lack of engagement by nuclear experts fearful of such mistrust can consequently create a self-fulfilling cycle that cuts off public engagement and participation and makes it less likely to occur.

\section{Dialogue}

Although participant 10 shared their fears of public engagement, they also were hopeful about future public engagement efforts. They noted, "this is a problem we already know how to solve. That's where rhetoric comes in," directly referencing the ways experts talk about nuclear energy. While only participant 10 used the term "rhetoric," the interviewees nearly collectively referenced the importance of communication in engaging the public around nuclear energy. Participant 8 noted that nuclear energy "has been an isolated field" that "should be more intertwined with other industries." They further argued that we must "train and motivate engineers [and scientists] to engage with the non-engineering part of nuclear: policy, education, risk, preparedness, and molding nuclear energy to fit with local cultures" (participant 8). Embracing the interdisciplinary and interconnected nature of nuclear, participant 8 forwarded the importance of dialogue and participation among various technical and public stakeholders, including educational spaces and local communities.

Participant 3 also highlighted the importance of being open to conversations, noting that it is important for experts to talk to non-experts "without being pompous" and without being dismissive of what they believe as "complete bologna." Participant 3's emphasis on not being "pompous" directly combats a monologue perspective of public audiences being inferior to nuclear experts. Instead, this view encourages a dialogue model of valuing participants as equal, or, at least, not as inferior. Participant 3, in part, evokes an IDM by focusing on explanation and one-way initial knowledge transfer, but tempers it with an emphasis on also providing opportunity for open discussions and active listening.

Participant 4 also pointed out problems with focusing on a lack of knowledge. They explained that there is a "perception of having to be a genius to understand nuclear" and some "people say "we need more education"” to change this misconception. However, participant 4 emphasized that instead of more education, we need to "change the idea of that education" by "moving away from the specifics of nuclear safety" and toward how nuclear energy directly relates to and affects the public. Participant 4 thereby evokes phronesis in thinking about the specific, tailored needs of their audience and how education is not simply a matter of deficits and quantity, but also accommodation and quality.

Four participants discussed having personal experiences talking with people where their dialogue partner, even when expressing fear of nuclear or apathy on the topic, became more open to nuclear energy as an option. These participants view their roles, at least in part, as ambassadors of nuclear energy to the public, in which communication and building trust plays an integral role. Referring to the difficulties of playing this role, participant 9 asks, "how do we communicate with a wide variety of stakeholders about the value of nuclear and get buy-in so those stakeholders will pressure their legislators, the EPA, and the government to bring it to their communities?" Locating the solution at the level of communication and public engagement, participant 9 notes that public activism around nuclear is an essential component to the future of nuclear energy (phronesis).

Other interviewees echoed the importance of bridging technical and public communities through public outreach, with some directly addressing whether the goal of nuclear should be persuasion or engagement. For example, participant 8 engaged eunoia when they stated that nuclear energy's needs are "not about changing public opinion, but how do we open dialogue between the nuclear community and the public so the public can build trust" with nuclear experts. By encouraging the public to share their voice, this interviewee considers it a responsibility of the industry to engage the public sincerely and without overtly persuasive goals or with the predetermined goal of nuclear being the solution. To achieve this open dialogue, interviewees offered examples of public engagement events, training nuclear scientists and engineers to be more effective communicators ("teach people in the industry how to have that conversation"-participant 9), and taking to social media to spread their contributions and information about nuclear energy online.

Participant 9 said, "people in the nuclear industry love [nuclear technologies] and are natural advocates who need to know how to respond better to personal connections and stories." Seeing nuclear experts as both industry professionals but also as members of the public, participant 9 exemplifies the role of the scientist citizen. Furthermore, they strongly indicate that this is not the current way many nuclear experts engage with the public, but that it should be. Interviewees commented that newer generations of nuclear experts are more interested in public engagement and issues of diversity and equity, including the impact of nuclear on marginalized communities. Participant 2 argued that nuclear power is "not an all or nothing deal" and "everything plays its part for the greater good," linking nuclear energy, in their mind, as a tool for advocate for the public's wellbeing (phronesis).

\section{Cost}

While the three other topoi had evidence of monologue and dialogue, cost uniquely employed only monologue features. Seeing cost as a primary barrier to broad-scale nuclear adoption, participant 4 explained that "time is money. The cost is so high that companies are unwilling or unable to choose nuclear." Such a conceptualization, echoed by many interviewees, ignores the risks and impacts to marginalized communities and the moral dimensions of nuclear by reducing everything to a matter of money. The topos of cost, for many interviewees, displaced other concerns, functioning as a gatekeeper to more dialoguebased perspectives. Responses consequently evoked a neoliberal perspective where a concern for funding deflects not only 
environmental concerns but also the human element of nuclear energy's impacts.

Some interviewees discussed how waste accumulating at the end of the fuel cycle requires the management, transportation, and storage of high-level waste, which is expensive (participants 3,5 , and 7). Participant 10 thought that concerns about the costs of nuclear waste disposal were exaggerated and were uniquely targeted at nuclear energy: "There's a lot of concern about longterm waste disposal that plagues nuclear and somehow does not plague any other energy form." This interviewee refers to how any source of commercial energy production will produce waste, but concern about costs does not seem to be equally distributed to the waste produced by non-nuclear energy sources.

A few participants explained that many front-loaded costs in constructing new plants ultimately pay off in the long term, but do not create an attractive investment for many companies due to high short-term costs and painstaking regulatory processes. In addition to building new plants, there is also a high cost associated with both maintaining and decommissioning old plants. Furthermore, reactor designs are continuously being evaluated and adjusted to higher standards, which a few interviewees (participants 1, 2, and 3) noted makes old plants costly to maintain.

Five of the interviewees agreed that nuclear energy struggles explicitly to compete with fossil fuels by cost due to the relatively high regulation over nuclear compared to other sources of energy, making nuclear inherently more expensive by comparison. Participant 12 noted that if nuclear power became "significantly cheaper" than other clean energy options, it would "eliminate public opinion" from the decision-making process, because people will rationally choose the energy option that is the cheapest. Similarly, participant 11 said that nuclear energy does not "have a level [financial] playing field for producing power and electricity," but if it were level, "nuclear would probably win." Not only does this perspective reject phronesis, but it also reduces energy decision-making solely to a matter of markets and economic competition (Bloomfield, 2019b).

One potentially encouraging theme in the cost topos surfaced as five of the interviewees suggested that increased inclusion of nuclear energy would result in a significantly cleaner and more reliable energy portfolio. These statements about environmental benefits, however, came in the form of a positive side effect to choosing nuclear rather than a decision-making priority.

\section{NUCLEAR ENERGY'S FUTURE}

The four topoi of risk and safety, government and policy, public education and engagement, and cost emerged across interviews as inventional resources for making sense of publictechnical relationships and interviewees' personal perceptions of their role and responsibilities as science communicators. Furthermore, these topoi serve as markers of key themes in nuclear rhetoric that inform perceptions of public-technical relationships. In other words, how nuclear experts negotiate these topoi configures potential collaborations or boundaries between public and technical actors on energy decisions. Framing nuclear energy through a monologue, for example, can close off considerations of public perceptions as valuable, legitimate, and reasonable, and further reifies technical spaces as the sole arenas of rationality. Alternatively, embracing dialogue fosters an attitude of scientists as citizens and public stakeholders as important and integral players in energy deliberation.

While this study focused on nuclear energy, we can preliminarily note that these topo $i$ are also likely to emerge across other scientific topics. For example, interviewee concerns about how to communicate safety and risk while maintaining credibility are also rife in health communication regarding COVID-19. Additionally, scientists involved in climate change research are no strangers to the politicization of their science that affects grant funding as administrations change. Many interviewees exhibited features of both monologue and dialogue, even when discussing the same topos, which indicates that the tensions underlying nuclear energy rhetoric and may underlie other scientific topics as well.

Notably, unlike the other three topoi, the topos of cost only brought forth features of monologue. This is an important finding because it suggests that engaging nuclear experts on topics of cost may invite a monologue perspective that closes opportunities for dialogue. When money is on the line, it seemed difficult for experts to see nuclear through a dialogue frame, including those who previously used dialogue features in other responses. While shifting conversations into areas such as the economy may be productive strategies for scientific topics such as climate change (Elliott, 2014; Bloomfield, 2019a), this strategy appears to be more fraught in nuclear energy. Instead, we propose that attempts to engage in collaboration with nuclear experts may avoid issues of cost and start from alternative grounds to ward off potentially defensive turns to monologue.

This analysis demonstrates that there are substantial barriers to technical-public collaboration rooted in experts' perceptions and attitudes. These barriers, however, also point to opportunities for fostering more public-technical collaboration and including public voices and the moral concerns of the scientist citizen in nuclear decision-making. As some interviewees noted, individuals who comprise the nuclear energy industry today are not those who built the bombs. As opposed to an interest in weaponry, our youngest interviewee became a nuclear scientist primarily for environmental reasons because they are "very concerned about climate change." As the industry changes, the dynamic of age and shifting generational perspectives are essential to consider. Centering new voices in the field who are more openly critical about nuclear, for example, could serve as an exemplar for the field to embrace vulnerability and honesty (arête) and value public participation in nuclear energy (phronesis) without fears of violating boundaries or the "proper" role of scientists and technical experts. Elevating these perspectives will come, in part, from creating opportunities for public-technical interactions, changing scientific curriculum to include public communication skills, and reducing barriers to experts acting as scientist citizens.

Additionally, the nuclear industry must actively include and address the concerns raised by those in opposition to nuclear energy. The values and cultures of marginalized communities 
such as Indigenous populations should be recognized and respected, unlike the environmental decision-making of past and current projects. To assist in the process of connecting the industry to public stakeholders energy communicators should explore opportunities to provide a platform for nuclear experts' voices and public voices to be shared and valued in decision-making. This paper is a preliminary step to understanding nuclear experts' conceptualization of technicalpublic interactions around nuclear energy, and we encourage more work on nuclear energy and other scientific topics along the lines of how to foster scientist citizens and publictechnical relationships.

In the unfolding nuclear debate, we hope that deliberations may take the form of dialogue as opposed to monologue. Based on these interviews, striving for dialogue will be tempered by foundational attitudes of monologue underlying many interviewees' responses. The impending consequences of climate change on people and the planet are the most pressing problems of our time. The role that nuclear energy plays in our environmental story is still being written, but we believe that a more sustainable future will be achieved with collaboration and dialogue between stakeholders across public and technical arenas.

\section{REFERENCES}

Besley, J. C., and Oh, S. H. (2013). The combined impact of attention to the Deepwater Horizon oil spill and environmental worldview on views about nuclear energy. Bull. Sci. Technol. Soc. 33, 158-171. doi: $10.1177 / 0270467614528901$

Besley, J. C., and Oh, S. H. (2014). The impact of accident attention, ideology, and environmentalism on American attitudes toward nuclear energy. Risk Anal. 34, 949-964. doi: 10.1111/risa.12151

Bloomfield, E. F. (2019a). Communication Strategies for Engaging Climate Skeptics: Religion and the Environment. New York, NY: Routledge.

Bloomfield, E. F. (2019b). The rhetoric of Energy Darwinism: neoliberal piety and market autonomy in economic discourse. Rhetor. Soc. Q. 49, 320-341. doi: 10.1080/02773945.2019.1634831

Bloomfield, E. F., and Tillery, D. (2019). The circulation of climate change denial online: rhetorical and networking strategies on Facebook. Environ. Commun. 13, 23-34. doi: 10.1080/17524032.2018.1527378

Bloomfield, E. F., van Swol, L. M., Chang, C. T., Willes, S., and Ahn, P. H. (2020). The effects of establishing intimacy and consubstantiality on group discussions about climate change solutions. Sci. Commun. 42, 369-394. doi: 10.1177/1075547020927017

Brook, B. W., and Bradshaw, C. J. A. (2014). Key role for nuclear energy in global biodiversity conservation. Conserv. Biol. 29, 702-712. doi: 10.1111/cobi. 12433

Cagle, L. E., and Tillery, D. (2015). Climate change research across disciplines: the value and uses of multidisciplinary research reviews for technical communications. Tech. Commun. Q. 24, 147-163. doi: $10.1080 / 10572252.2015 .1001296$

Cagle, L. E., and Tillery, D. (2018). "Tweeting the anthropocene," in Scientific Communication: Practices, Theories, and Pedagogies, eds H. Yu and K. M. Northcut (New York, NY: Routledge), 131-148.

Ceccarelli, L. (2020). The polysemic facepalm: Fauci as rhetorically savvy scientist citizen. Philos. Rhetor. 53, 239-245. doi: 10.5325/philrhet.53.3.0239

Cloud, D. (2020). The corrupted scientist archetype and its implications for climate change communication and public perceptions of science. Environ. Commun. 14, 816-829. doi: 10.1080/17524032.2020. 1741420

de Romilly, J. (1958). Eunoia in isocrates or the political importance of creating good will. J. Hellenic Stud. 78, 92-101. doi: 10.2307/628928

\section{DATA AVAILABILITY STATEMENT}

The raw data supporting the conclusions of this article will be made available by the authors, without undue reservation.

\section{ETHICS STATEMENT}

The studies involving human participants were reviewed and approved by Institutional Review Board, UNLV. The participants provided their written informed consent to participate in this study.

\section{AUTHOR CONTRIBUTIONS}

HP performed the interviews and drafted the paper. EB and HP edited the paper. All authors contributed to the article and approved the submitted version.

\section{FUNDING}

The publication fees for this article were supported by the UNLV University Libraries Open Article Fund.

Ecklund, E. H., James, S. A., and Lincoln, A. E. (2012). How academic biologists and physicists view science outreach. PLoS ONE 7, e36240. doi: 10.1371/journal.pone.0036240

Elliott, K. C. (2014). Anthropocentric indirect arguments for environmental protection. Ethics Policy Environ. 17, 243-260. doi: 10.1080/21550085.2014.955311

Endres, D. (2009a). The rhetoric of nuclear colonialism: rhetorical exclusion of American Indian arguments in the Yucca Mountain nuclear waste siting decision. Commun. Crit. Cult. Stud. 6, 39-60. doi: 10.1080/147914208026 32103

Endres, D. (2009b). Science and public participation: an analysis of public scientific argument in the Yucca Mountain controversy. Environ. Commun. 3, 49-75. doi: $10.1080 / 17524030802704369$

Endres, D. (2012). Sacred land or national sacrifice zone: The role of values in the Yucca Mountain participation process. Environ. Commun. 6, 328-345. doi: $10.1080 / 17524032.2012 .688060$

Endres, D., Cozen, B., O'Byrne, M., Feldspausch-Parker, A., and Peterson, T. R. (2016). Putting the $U$ in carbon capture and storage: rhetorical boundary negotiation within the CCS/CCUS scientific community. J. Appl. Commun. Res. 44, 362-380. doi: 10.1080/00909882.2016. 1225160

Fahnestock, J. (1986). Accommodating science: the rhetorical life of scientific facts. Written Commun. 15, 330-350. doi: 10.1177/0741088398015003006

Farrell, T. B., and Goodnight, G. T. (1981). Accidental rhetoric: the root metaphors of three Mile Island. Commun. Monogr. 48, 271-300. doi: 10.1080/03637758109376063

Fernández, R. J. (2016). How to be a more effective environmental scientist in management and policy contexts. Environ. Sci. Policy 64, 171-176. doi: 10.1016/j.envsci.2016.07.006

Goodin, A. S. (2013). Sovereign conflicts and divided loyalties: native American survivance in the era of nuclear modernity - a story of the Western Shoshone and their response to the Yucca Mountain high-level radioactive waste repository (Publication No. 3588067) (Doctoral dissertation). University of New Mexico, ProQuest Dissertations Publishing, Albequerque, NM, United States.

Goodnight, G. T. (2005). Science and technology controversy: a rationale for inquiry. Argumentation Advocacy 42, 26-29. doi: 10.1080/00028533.2005.11821636

Gross, A. G. (1994). The roles of rhetoric in the public understanding of science. Public Understand. Sci. 3, 3-23. doi: 10.1088/0963-6625/3/1/001 
Gusterson, H. (1996). Nuclear Rites: A Weapons Laboratory at the End of the Cold War. Berkeley, CA: University of California Press.

Hacker, M., Beyer, T., Baum, R. P., Kalemis, A., Lammertsma, A. A., Lewington, V., et al. (2015). Nuclear medicine innovations help (drive) healthcare (benefits). Euro. J. Nucl. Med. Mol. Imaging 42, 173-175. doi: 10.1007/s00259-0142957-6

Harris, J., Hassall, M., Muriuki, G., Warnaar-Notschaele, C., McFarland, E., and Ashworth, P. (2018). The demographics of nuclear power: comparing nuclear experts', scientists' and non-science professionals' views of risk, benefits and values. Energy Res. Soc. Sci. 46, 29-39. doi: 10.1016/j.erss.2018. 05.035

Hart, P. S., and Nisbet, E. C. (2012). Boomerang effects in science communication: how motivated reasoning and identity cues amplify opinion polarization about climate mitigation policies. Communic. Res. 39, 701-723. doi: $10.1177 / 0093650211416646$

Ho, S. S., and Kristiansen, S. (2019). Environmental debates over nuclear energy: media, communication, and the public. Environ. Commun. 13, 431-439. doi: $10.1080 / 17524032.2019 .1603018$

Ho, S. S., Leong, A. D., Looi, J., Chen, L., Pang, N., and Tandoc, E. (2019). Science literacy or value predisposition? A meta-analysis of factors predicting public perceptions of benefits, risks, and acceptance of nuclear energy. Environ. Commun. 13, 457-471. doi: 10.1080/17524032.2017.1394891

Holifield, R., Chakraborty, J., and Walker, G. (eds). (2017). The Routledge Handbook of Environmental Justice. London: Routledge.

Hynes, H. P. (2013). Climate change, nuclear power, and renewable energy: environmental reality vs political rhetoric. Peace Freedom 73, 19-20.

Johannesen, R. L. (1974). Attitude of speaker toward audience: A significant concept for contemporary rhetorical theory and criticism. Cent. States Speech J. 25, 95-104. doi: 10.1080/10510977409367774

Kharecha, P. A., and Hansen, J. E. (2013). Prevented mortality and greenhouse gas emissions from historical and projected nuclear power. Environ. Sci. Technol. 47, 6718-6719. doi: 10.1021/es402211m

Kim, Y., Kim, M., and Kim, W. (2013). Effect of the Fukushima nuclear disaster on global public acceptance of nuclear energy. Energy Policy 61, 822-828. doi: 10.1016/j.enpol.2013.06.107

Kinsella, W. J. (1996). A "fusion" of interests: big science, government, and rhetorical practice in nuclear fusion research. Rhetoric Soc. Q. 26, 65-81. doi: 10.1080/02773949609391079

Kinsella, W. J. (1999). Discourse, power, and knowledge in the management of "big science" the production of consensus in a nuclear fusion research laboratory. Manag. Commun. Q. 13, 171-208. doi: 10.1177/0893318999 132001

Kinsella, W. J. (2005). "One hundred years of nuclear discourse: four master themes and their implications for environmental communication," in The Environmental Communication Yearbook, ed S. L. Senecah (Routledge), 49-72.

Kinsella, W. J. (2012). Environments, risks, and the limits of representation: examples from nuclear energy and some implications of Fukushima. Environ. Commun. 6, 251-259. doi: 10.1080/17524032.2012. 672928

Kinsella, W. J., Andreas, D. C., and Endres, D. (2015). Communicating nuclear power: a programmatic review. Ann. Int. Commun. Assoc. 39, 277-309. doi: 10.1080/23808985.2015.11679178

Klenke, C. (2020). Yucca Mountain Research Collection. University Libraries, University of Nevada, Las Vegas, NV. Available online at: https:/guides.library. unr.edu/yuccamountain/collectionhistory

Kotcher, J. E., Myers, T. A., Vraga, E. K., Stenhouse, N., and Maibach, E. W. (2017). Does engagement in advocacy hurt the credibility of scientists? Results from a randomized national survey experiment. Environ. Commun. 11, 415-429. doi: $10.1080 / 17524032.2016 .1275736$

Latour, B. (2014). Agency at the time of the anthropocene. New Lit. Hist. 45, 1-18. doi: $10.1353 /$ nlh.2014.0003

Lewis, W. B. (1953). The Accident to the NRX Reactor on December 12, 1952. Atomic Energy of Canada Limited. AECL 232. Available onlinne at: https:// www.osti.gov/servlets/purl/4379334

Lynch, L. (2012). "We don't wanna be radiated": documentary film and the evolving rhetoric of nuclear energy activism. Am. Literature 84, 327-351. doi: $10.1215 / 00029831-1587368$
Marteau, T. M., Sowden, A. J., and Armstrong, D. (2002). "Implementing research findings into practice: beyond the information deficit model," in Getting Research Findings Into Practice, eds A. Haines and A. Donald (London: BMJ Books), 68-76.

McFadden, B. (2016). Examining the gap between science and public opinion about genetically modified food and global warming. PLoS ONE 11, e0166140. doi: 10.1371 /journal.pone. 0166140

National Atomic Testing Museum (2021). Personal Visit. Las Vegas, NV.

Novikau, A. (2017). What is "Chernobyl syndrome?" The use of radiophobia in nuclear communications. Environ. Commun. 11, 800-809. doi: $10.1080 / 17524032.2016 .1269823$

Pietrucci, P., and Ceccarelli, L. (2019). Scientist citizens: rhetoric and responsibility in L'Aquila. Rhetoric Public Affairs 22, 95-128. doi: 10.14321/rhetpublaffa.22.1.0095

Prăvălie, R., and Bandoc, G. (2018). Nuclear energy: between global electricity demand, worldwide decarbonization imperativeness, and planetary environmental implications. J. Environ. Manage. 209, 81-92. doi: 10.1016/j.jenvman.2017.12.043

Reverby, S. M. (2021). Racism, disease, and vaccine refusal: people of color are dying for access to COVID-19 vaccines. PLoS Biol. 19, e3001167. doi: 10.1371/journal.pbio.3001167

Rich, V. (1986). Chernobyl accident is blamed on human error. Nature 332, 295. doi: $10.1038 / 322295 \mathrm{a} 0$

Ross, D. G. (2017). Topic-Driven Environmental Rhetoric. New York, NY: Routledge.

Santos, L. J. (2021). Half Lives: The Unlikely History of Radium. New York, NY: Simon \& Schuster.

Saraç-Lesavre, B., and Laurent, B. (2019). Stress-testing Europe: normalizing the post-Fukushima crisis. Minerva 57, 239-260. doi: 10.1007/s11024-018-9362-4

Schweitzer, J., and Mix, T. L. (2021a). "It is a tradition in the nuclear industry...secrecy": political opportunity structures and nuclear knowledge production in France. Sociol. Res. Online 1-21. doi: $10.1177 / 13607804211025052$

Schweitzer, J., and Mix, T. L. (2021b). "Personally, it does not bother met all that much": Nuclear risk assessments and strategic choice among stakeholders in post-Fukushima France. Sociol. Focus 54, 331-348. doi: $10.1080 / 00380237.2021 .1970063$

Serp, J., Poinssot, C., and Bourg, S. (2017). Assessment of the anticipated environmental footprint of future nuclear energy systems. Evidence of the beneficial effect of extensive recycling. Energies 10, 1445-1464. doi: $10.3390 /$ en10091445

Shim, J., Park, C., and Wilding, M. (2015). Identifying policy frames through semantic network analysis: an examination of nuclear energy policy across six countries. Policy Sci. 48, 51-83. doi: 10.1007/s11077-0159211-3

Sowards, S. K. (2012). Environmental justice in international contexts: understanding intersections for social justice in the twenty-first century. Environ. Commun. 6, 285-289. doi: 10.1080/17524032.2012. 700205

Stoffle, R. W., and Evans, M. J. (1988). American Indians and nuclear waste storage: the debate at Yucca Mountain, Nevada. Policy Stud. J. 16, 751-767. doi: 10.1111/j.1541-0072.1988.tb00684.x

Summers, I., Agee, A., Scott, M. R., and Endres, D. (2019). "The discursive construction of the anti-nuclear activist," in Networking Argument, ed C. Winkler (New York, NY: Routledge), 115-121.

Tateno, S., and Yokoyama, H. M. (2013). Public anxiety, trust, and the role of mediators in communicating risk of exposure to low dose radiation after the Fukushima Daiichi Nuclear Plant explosion. J. Sci. Commun. 12, 1-22. doi: $10.22323 / 2.12020203$

Thakur, R. (2013). Follow the yellowcake road: balancing Australia's national interests against international anti-nuclear interests. Int. Aff. 89, 943-961. doi: $10.1111 / 1468-2346.12053$

Tillery, D. (2018). Commonplaces of Scientific Evidence in Environmental Discourses. New York, NY: Routledge.

Tomonaga, M. (2019). The atomic bombings of Hiroshima and Nagasaki: a summary of the human consequences, 1945-2018, and lessons for Homo sapiens to end the nuclear weapon age. J. Peace Nucl. Disarmament 2, 491-517. doi: 10.1080/25751654.2019.1681226 
Waldman, S., and Heikkinen, N. (2018). As climate scientists speak out, sexist attacks are on the rise. E\&E News. Available online at: https://www. scientificamerican.com/article/as-climate-scientists-speak-out-sexist-attacksare-on-the-rise/

Walsh, L. (2010). Before climategate: visual strategies to integrate ethos across the "is/ought" divide in the IPCC's Climate Change 2007: summary for policy makers. Poroi 6, 33-61. doi: 10.13008/2151-2957.1066

Zhu, W., Wei, J., and Zhao, D. (2016). Anti-nuclear behavioral intentions: the role of perceived knowledge, information processing, and risk perceptions. Energy Policy 88, 168-177. doi: 10.1016/j.enpol.2015.10.009

Conflict of Interest: The authors declare that the research was conducted in the absence of any commercial or financial relationships that could be construed as a potential conflict of interest.
Publisher's Note: All claims expressed in this article are solely those of the authors and do not necessarily represent those of their affiliated organizations, or those of the publisher, the editors and the reviewers. Any product that may be evaluated in this article, or claim that may be made by its manufacturer, is not guaranteed or endorsed by the publisher.

Copyright (c) 2022 Patenaude and Bloomfield. This is an open-access article distributed under the terms of the Creative Commons Attribution License (CC BY). The use, distribution or reproduction in other forums is permitted, provided the original author(s) and the copyright owner(s) are credited and that the original publication in this journal is cited, in accordance with accepted academic practice. No use, distribution or reproduction is permitted which does not comply with these terms. 


\section{APPENDIX}

\section{Interview Questions}

1. What is your role in the nuclear field, and what led you to this point?

2. Why is nuclear energy important to you?

3. What obstacles do you see the nuclear energy industry facing, and what do you foresee the nuclear energy industry will face in the future?

4. How do you think the public views nuclear energy? Followups: Do you think those perceptions are a problem/why? How do you think we could change the perceptions of nuclear energy?
5. Have there been instances in your career where the political discourse about nuclear energy has affected your work or the work of people you know? Follow-ups: How do you respond in those situations, if at all?

6. Are there any specific public misconceptions that have impacted your work or the work of people you know? Followups: How do you respond in those situations, if at all?

7. What effect do you think the next generation/incoming generations of nuclear scientists and engineers will have on the nuclear energy industry?

8. What is the most important thing you want people to know about nuclear energy? 